\title{
Crystallization mechanisms in cream during ripening and initial butter churning
}

\author{
Patrizia Buldo, ${ }^{*}$ Jacob J. K. Kirkensgaard, $†$ and Lars Wiking ${ }^{* 1}$ \\ *Department of Food Science, Aarhus University, Blichers Allé 20, PO Box 50, 8830 Tjele, Denmark \\ †Niels Bohr Institute, University of Copenhagen, Blegdamsvej 17, 2100 Copenhagen, Denmark
}

\begin{abstract}
The temperature treatment of cream is the time-consuming step in butter production. A better understanding of the mechanisms leading to partial coalescence, such as fat crystallization during ripening and churning of the cream, will contribute to optimization of the production process. In this study, ripening and churning of cream were performed in a rheometer cell and the mechanisms of cream crystallization during churning of the cream, including the effect of ripening time, were investigated to understand how churning time and partial coalescence are affected. Crystallization mechanisms were studied as function of time by differential scanning calorimetry, nuclear magnetic resonance and by X-ray scattering. Microstructure formation was investigated by small deformation rheology and static light scattering. The study demonstrated that viscosity measurements can be used to detect phase inversion of the emulsion during churning of the cream in a rheometer cell. Longer ripening time (e.g., $5 \mathrm{~h}$ vs. $0 \mathrm{~h}$ ) resulted in larger butter grains (91 vs. $52 \mu \mathrm{m}$ ), higher viscosity ( 5.3 vs. $1.3 \mathrm{~Pa} \cdot \mathrm{s}$ ), and solid fat content (41 vs. $13 \%$ ). Both ripening and churning time had an effect on the thermal behavior of the cream. Despite the increase in solid fat content, no further changes in crystal polymorphism and in melting behavior were observed after $1 \mathrm{~h}$ of ripening and after churning. The churning time significantly decreased after $0.5 \mathrm{~h}$ of ripening, from $22.9 \mathrm{~min}$ for the cream where no ripening was applied to $16.23 \mathrm{~min}$. Therefore, the crystallization state that promotes partial coalescence (i.e., aggregation of butter grains) is obtained within the first hour of cream ripening at $10^{\circ} \mathrm{C}$. The present study adds knowledge on the fundamental processes of crystallization and polymorphism of milk fat occurring during ripening and churning of cream. In addition, the dairy industry will benefit from these insights on the optimization of butter manufacturing.
\end{abstract}

Received August 17, 2012.

Accepted July 27, 2013.

${ }^{1}$ Corresponding author: lars.wiking@agrsci.dk
Key words: partial coalescence, milk fat crystallization, viscosity, butter

\section{INTRODUCTION}

In many dairy products, such as butter, ice cream, and whipped cream, the presence of fat crystals in the fat globules of the emulsion and partial coalescence phenomenon are required to obtain the desired product (Darling, 1982; Barfod and Krog, 1987; Boode and Walstra, 1993; Goff, 1997). The partial coalescence phenomenon occurs when a crystal present at the interface of the fat globule penetrates the milk fat globule membrane and binds another fat globule (van Boekel and Walstra, 1981a; Boode and Walstra, 1993). When partial coalescence has started, oil will be release out of the globules, continuing until the formed network is wetted by oil (Boode et al., 1993). Thereafter, a network made of aggregated fat globules will be formed. Fat globules retain most of their original shape but are linked by a semisolid connection; therefore, the process is called partial coalescence (Boode, 1992; Goff, 1997). The semisolid connection supports the original shape of the globules aggregated against complete coalescence, which is driven by Laplace pressure (Boode et al., 1993). In general, partial coalescence is initiated by shear and halted by the resistance from the semisolid connections (van Boekel and Walstra, 1981b; Goff, 1997).

The thermal treatment of the cream influences the extent and rate of partial coalescence of milk fat globules, thereafter the macroscopic properties of the product (Boode, 1992; Drelon et al., 2006). The thermal treatment of the cream, also known as ripening, is the most time-consuming step in butter production; however, it governs the crystallization of the fat and thereafter the consistency of the butter. Consistency mainly refers to the hardness, stiffness, viscosity, adhesiveness, and spreadability of the product. The thermal treatment of the cream is designed based on the triacylglycerol (TAG) composition and on the iodine value (amount of unsaturation in FA) of the cream. An example of thermal treatment is the cold-warmcold method, also known as the Swedish or Alnarp 
6-12-6 method (Samuelsson and Petersson, 1937). This method is usually applied for winter cream and the resultant butter is softer, due to the higher amount of liquid fat in the continuous phase. After the ripening step, the cream is churned and worked and during these steps milk fat globules aggregate to form butter grains. Aggregation of butter grains leads to a phase inversion of the emulsion and entails the separation of the water phase (the buttermilk). Triacylglycerols have the ability to crystallize in different polymorphic forms with different lamellar stackings and hence have different melting points, which increase with increasing crystal stability. The longitudinal organizations (stackings) of TAG in lamellar structures correspond to double $(\mathbf{2 L})$ or triple $(\mathbf{3 L})$ chain length structures. The stackings of the TAG molecules, called long spacings, are studied by small-angle scattering and the measured thickness for the $2 \mathrm{~L}$ and $3 \mathrm{~L}$ structure is 40 to $50 \AA$ and 55 to $75 \AA$, respectively (Small, 1986; Larsson and Larsson, 1994). The polymorphic forms are identified by the crystal subcellular structures that characterize the crosssectional packing modes of the zigzag aliphatic chain, called short spacings (Sato, 2001). The polymorphic forms identified in milk are $\alpha, \beta^{\prime}$, and $\beta$, which correspond to the hexagonal, orthorhombic, and triclinic packing of the sub-cells, respectively. These packings are studied by wide-angle scattering. The $\alpha$ form is characterized by a diffraction peak at $4.15 \AA$, the $\beta^{\prime}$ form by 2 diffraction peaks at 3.8 and $4.2 \AA$, and the $\beta$ form by a peak at $4.6 \AA$ among other peaks (Small, 1986; Larsson and Larsson, 1994).

Destabilization of the emulsion and partial coalescence occurring during churning of the cream is an extremely complex phenomenon. Previous studies have shown the role of fat crystals in the mechanisms of physical instability in oil in water food emulsions and in inducing partial coalescence of emulsion droplets (Rousseau, 2000; Fredrick et al., 2010). Funahashi and Horiuchi (2008) demonstrated, by using an artificial neural network, that the characteristics of the churning process in continuous butter manufacture are influenced by the fat content of the cream, the cream flow rate, and by the cream feed temperature, which influence the water content of the butter. Furthermore, Bugeat et al. (2011) showed the effect of unsaturated FA and emulsion droplet size on the crystallization behavior of milk fat TAG. Although milk fat crystallization is important for its functionality and application, the literature is scant on the mechanism of milk fat crystallization in emulsion systems. Knowledge on mechanisms leading to milk fat crystallization in emulsions, and thus to partial coalescence, will contribute to the optimization of the production process of fat-based dairy products. The aim of this study was to elucidate the mechanisms lead- ing to milk fat crystallization in emulsions, and thus to partial coalescence, during churning of the cream, including the effect of ripening time.

\section{MATERIALS AND METHODS}

\section{Materials}

Commercial winter cream (Arla Foods, Viby J, Denmark) with $38 \%$ fat was used for the ripening and churning of the cream.

\section{FA Determination}

Fatty acid composition was determined by gas chromatography after methylation of the lipids, as described by Wiking et al. (2009).

\section{Churning Experiment and Viscosity Measurements}

Churning was simulated at a laboratory scale by using a rheometer (AR-G2; TA Instruments Inc., New Castle, DE) supplied with a starch cell. This geometry consists of a cup surrounded by a jacket and an impeller. A gap of $5.5 \mathrm{~mm}$ was used. One-third of the cell $(30 \mathrm{~mL})$ was filled with cream. To erase the thermal history of the cream, it was heated at $60^{\circ} \mathrm{C}$ for $15 \mathrm{~min}$. Afterward, a ripening step was performed. The cream was cooled to $10^{\circ} \mathrm{C}$ at $5^{\circ} \mathrm{C} / \mathrm{min}$ and held there for $0,0.5$, 1,5 , and $17 \mathrm{~h}$, respectively. During the heating and the ripening steps, a shear equal to $0.5 \mathrm{rad} / \mathrm{s}$ was applied to produce homogeneous crystallization. After the ripening step, the temperature was increased to $13^{\circ} \mathrm{C}$ at $5^{\circ} \mathrm{C} /$ min, and churning was simulated. The shear applied was $100 \mathrm{rad} / \mathrm{s}$ and it was performed until butter grains aggregation occurred; thus, phase inversion of the emulsion was achieved. During the whole process, changes in viscosity $(\mathrm{Pa} \cdot \mathrm{s})$ were investigated as a function of time. The viscosity of the crystallizing sample was plotted as a function of churning time. Each analysis was executed at least in triplicate.

\section{Analysis of Butter Grain Size}

By measuring the size distribution at different stages of ripening and churning of the cream, it was possible to follow the formation of the fat globule aggregation. Globule size distributions were measured by static light scattering (Mastersizer 2000; Malvern Instruments Ltd., Malvern, UK). Measurements were performed every hour during ripening, and approximately every 5 min during churning, with the exception of the cream ripened for $0.5 \mathrm{~h}$, where the particle size was not measured after $5 \mathrm{~min}$ of churning. The refractive indices 
used for milk fat globules and water were 1.458 and 1.33, respectively. At least triplicate measurements were performed for each sample.

\section{Studies of Melting Behavior by Differential Scanning Calorimetry}

The thermal behavior of the samples was studied during ripening and churning of the cream using a differential scanning calorimeter (Q 2000 DSC; TA Instruments, Elstree, UK). Between 4 and $10 \mathrm{mg}$ of sample was loaded in a hermetically sealed aluminum pan. The reference used was an empty, hermetically sealed aluminum pan. Measurements were carried out from the ripening or churning temperature $\left(10\right.$ or $\left.13^{\circ} \mathrm{C}\right)$ to $60^{\circ} \mathrm{C}$ at a rate of $5^{\circ} \mathrm{C} / \mathrm{min}$. The formed butter grains were also analyzed right after the phase inversion of the emulsion occurred. The thermal history of the samples before differential scanning calorimetry analysis was identical to that experienced on the Mastersizer particle size analyzer. These samples were obtained directly from the starch cell during the ripening and churning of the cream. Each analysis was executed at least in triplicate.

\section{Solid Fat Content Determination During Ripening and Churning of Cream}

The solid fat content (SFC) was measured by lowfield pulsed nuclear magnetic resonance (Resonance Maran Ultra analyzer; Oxford Instruments, Abingdon, UK) by using the direct method. The measurements were performed at selected ripening times $(0,0.5,1$, 5 , and $17 \mathrm{~h}$ ), churning time (7 min after churning), and just before butter grains aggregation occurred. The latter was determined visually, by observing the online viscosity versus churning time plot. The point where the slope of the viscosity changed toward higher values was identified after several preliminary observations as the point just before butter grains aggregation occurred. All the samples were run in quadruplicate.

\section{Analysis of Polymorphic Crystal Forms by Small- and Wide-Angle X-Ray Scattering}

The polymorphism of the fat crystals in the milk fat globules was evaluated during ripening and churning of the cream by combined small- and wide-angle X-ray scattering measurements. The ripening step was simulated by applying the same temperature $\left(10^{\circ} \mathrm{C}\right)$ used in the starch cell, whereas the churning step was simulated in a tabletop blender (CombiMax 600; Braun, Kronberg, Germany) at maximum speed (unknown shear force). After churning, the cream was ripened for approximately $1 \mathrm{~h}$ at $10^{\circ} \mathrm{C}$. Samples were investigated right after the ripening step, after 2.14 and 3.4 min of churning, and on butter grains. To exclude the possibility that scattering signals could arise from the casein micelles, skim milk ( $0.1 \%$ fat) was analyzed, without finding any scattering (data not shown).

The X-ray scattering was performed using a smallangle X-ray scattering (SAXS) instrument (JJ X-Ray A/S, Kongens Lyngby, Denmark), equipped with a 100XL+ micro-focus sealed X-ray tube from Rigaku Europe SE (Ettlingen, Germany) and a 2D 300K Pilatus detector from Dectris Ltd. (Baden, Switzerland). Measurements were performed with a pinhole collimated beam, with the detector positioned asymmetrically to yield a single measurement q-range of 0.05 to 2.8 $\AA^{-1}$, with the magnitude of the scattering vector defined by $\mathrm{q}=4 \pi / \lambda \sin (\theta)$, where $\lambda=1.54 \AA$ is the $\mathrm{X}$-ray wavelength and $\theta$ is half of the scattering angle. This q-range corresponds to scattering angles between 0.7 and 40 degrees or equivalent distances between 125 and $2.25 \AA$. Thus, in this setting, all relevant peak information for both short and long spacings can be obtained in a single measurement. The samples were loaded in sample holders sealed with 5 - to 7 - $\mu$ m-thick mica windows. The background scattering from the mica was subtracted from the sample spectra. The sample holders were loaded onto a temperature-controlled sample stage from Linkam Scientific Instruments Ltd. (Guildford, UK). The polymorphism of oil droplets was classified into $\alpha, \beta^{\prime}$, and $\beta$ from the scattering patterns according to Lopez et al. (2000).

\section{Statistical Analysis}

All data were statistically analyzed by 2-way ANOVA (SAS Institute Inc., Cary, NC) to determine the relationship between the ripening and churning time.

\section{RESULTS AND DISCUSSION}

\section{Relationship Between Viscosity and Particle Size Distribution During Ripening and Churning of the Cream}

The change in viscosity of the cream was measured as a function of the ripening and churning time. Final churning (i.e., when phase inversion of the emulsion occurred) is presently defined as the highest viscosity value. It was observed that by increasing the ripening time, the churning time decreased and the final viscosity increased (Figure 1). Cream ripened for 17 $\mathrm{h}$ resulted in a short churning time of $14.05 \pm 0.02$ min, whereas a churning time of $22.9 \pm 0.65$ min was needed for the cream where no ripening was applied. Independent of the ripening time used, no significant 


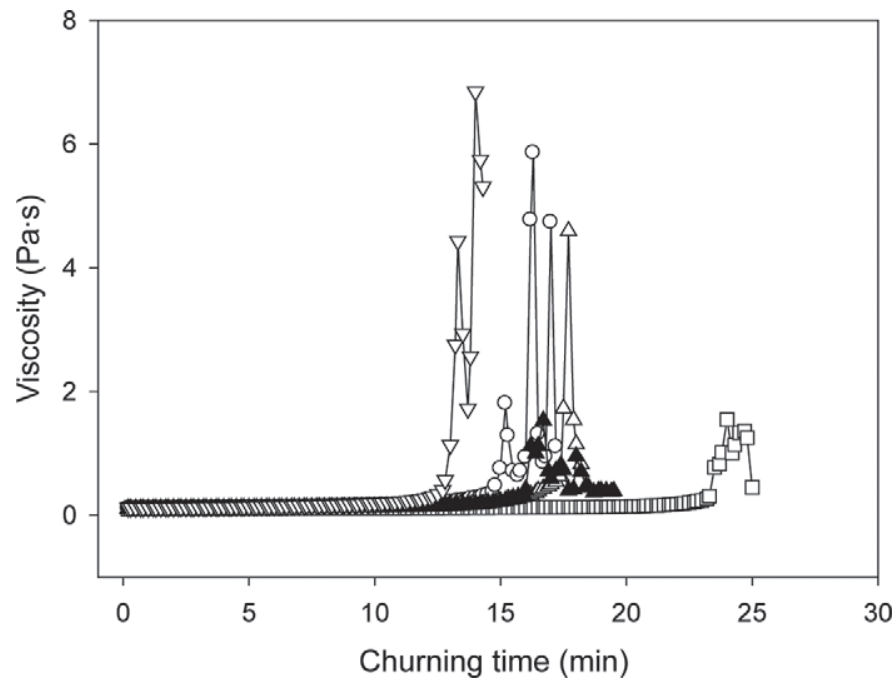

Figure 1. Changes in viscosity $(\mathrm{Pa} \cdot \mathrm{s})$ during churning $(\mathrm{min})$ in cream samples ripened for $0(\square), 0.5(\mathbf{\Lambda}), 1(\Delta), 5(\bigcirc)$, and $17 \mathrm{~h}(\nabla)$. Churning was performed at $100 \mathrm{rad} / \mathrm{s}$.

change in viscosity was observed during the ripening of the cream (data not shown) and at the beginning of the churning (i.e., during the first 22 min of churning for the cream ripened for $0 \mathrm{~h}$ and during the first $13 \mathrm{~min}$ of churning for the cream ripened for $17 \mathrm{~h}$; Figure 1). As shown in Figure 1, the viscosity of the cream suddenly increased from $0 \mathrm{~Pa} \cdot \mathrm{s}$ and up to $1.3,1.6,4.9,5.3$, and $6.9 \mathrm{~Pa} \cdot \mathrm{s}$ for the sample ripened for $0,0.5,1,5$, and $17 \mathrm{~h}$ respectively. The highest viscosity value corresponded to aggregation of butter grains with simultaneous separation of buttermilk. As soon as phase inversion of the emulsion occurred, the rheometer started measuring the viscosity of the buttermilk as well, which presumably explains the decrease in viscosity reported after the highest point.

In cream, fats are present in the globular structure and consequently crystallization occurs inside the globules during the ripening step. The crystals formed inside the globules do not contribute to the increase in viscosity because the volume fraction of the dispersion phase does not change. This explains the constant viscosity observed during the thermal treatment at the beginning of churning (Figure 1). The jump in viscosity was due to aggregation of butter grains, which formed a network made of irregular aggregates as a consequence of the churning process. The formation of a network made of partially coalesced globules, thus aggregated crystals, increases the viscosity of the emulsion by increasing the volume fraction of the dispersed phase (Boode, 1992; Johansson D., 1994).

By measuring the particle size distribution, it was possible to follow the level of partial coalescence during ripening and churning of the cream. Figure 2 shows the effect of ripening time on particle size distribution. By increasing the ripening time, the degree of partial coalescence increases, as the final average particle size of the butter grains was $52,60,70$, and $91 \mu \mathrm{m}$ for cream ripened for $0,0.5,1$, and $5 \mathrm{~h}$, respectively. Although the ripening time influenced the crystallization and particle size distribution, the shear force is a fundamental factor for partial coalescence to occur. In this study, no changes in droplet size measurements were observed during the ripening step, independent of the ripening time used (Figure 2). The effect of different shear intensities and type should also be considered when studying fat crystallization and partial coalescence; for instance, when comparing fat crystallization performed in a model system as in the present study, with the typical continuous butter-making machine, which is characterized by higher air intake during churning. The latter increases the nucleation rate, which in turn affects crystal formation and growth, whereas the shear type influences the flow of the fat globules and thus their probability of encounter. The balance between the shear force, the interglobule forces and the susceptibility to rupture of the milk fat globule membrane between approaching globules led to partial coalescence and thus aggregation of fat globules. In emulsion systems, the shear force can overcome the interglobule forces and rupture the membrane between the 2 globules, causing formation of clumps or clusters (Xu et al., 2005). Moreover, by decreasing the interparticle distance between globules, both by increasing the particle size and by applying shear, the probability and the duration of encounters increase. These factors increase the probability of penetration of fat crystals and thus partial coalescence and butter grain aggregation are favored (van Boekel and Walstra, 1981b; Vanapalli et al., 2002). Consequently, once aggregation between globules started, the increase in diameter was faster than at the beginning of churning (Figure 2). Longer ripening time led to a higher rate of fat crystallization and thus to a higher degree of partial coalescence and to larger particles in the emulsion. From this study, the minimum average particle size needed to obtain phase inversion of the emulsion, as detected by viscosity, was approximately $52 \mu \mathrm{m}$. The highest level of partial coalescence was obtained on cream ripened for the longest time, which also led to the shortest churning time.

\section{Mechanisms Leading to Partial Coalescence}

In Figure 3, the level of SFC measured after ripening, after churning of the cream for $7 \mathrm{~min}$, and just before butter grains aggregation occurred is shown for cream ripened for $0,0.5,1,5$ and $17 \mathrm{~h}$. As expected, a 

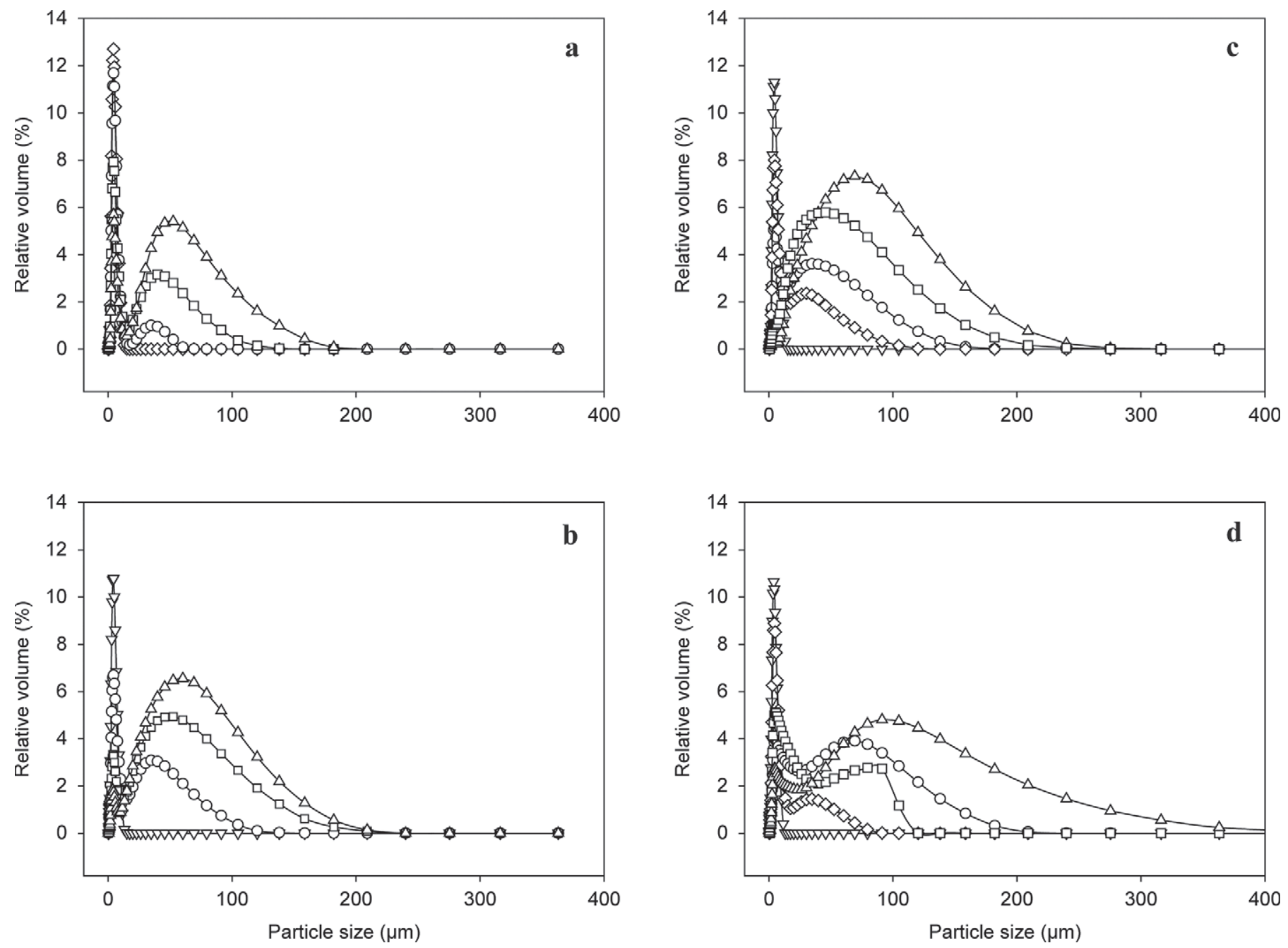

Figure 2. Particle size distribution for cream ripened for 0 (a), 0.5 (b), 1 (c), and $5 \mathrm{~h}$ (d). $\nabla=$ after ripening of the cream for $0.5,1$, and 5 $\mathrm{h} ; \diamond=$ after $5 \mathrm{~min}$ and $\bigcirc=$ after $10 \mathrm{~min}$ of churning; $\square=$ just before butter grains aggregation occurred; $\Delta=$ the final butter grains.

significant increase in SFC was observed by increasing the ripening time (Figure 3). The SFC obtained after $17 \mathrm{~h}$ of cream ripening was not considered to differ much from the cream ripened for $5 \mathrm{~h}$, despite its higher value $(43.24 \pm 0.24$ vs. $41.21 \pm 0.30 \%)$. Therefore, for the cream ripened for $17 \mathrm{~h}$, the level of SFC after 7 and $11 \mathrm{~min}$ of churning was not measured. After $7 \mathrm{~min}$ of churning the cream at $100 \mathrm{rad} / \mathrm{s}$, the $\mathrm{SFC}$ significantly decreased for the cream ripened at $0.5,1$, and 5 $\mathrm{h}$ (Figure 3). This decrease was due to the increase in temperature from $10^{\circ} \mathrm{C}$ for ripening to $13^{\circ} \mathrm{C}$ for churning. Just before phase inversion of the emulsion, the level of SFC was the same as the one obtained after 7 min (Figure 3). The higher temperature of the churning step melted part of the solid fat in the emulsion and thus more liquid fat was available. Relating to final viscosity and average diameter of butter grains, greater SFC led to an increase in those. Increasing the SFC from $15 \%$ (for the sample not ripened) to $23 \%$ (for the sample ripened for $0.5 \mathrm{~h}$ ) significantly decreased the churning time from $22.9 \pm 0.65$ to $16.23 \pm 0.6 \mathrm{~min}$; further increases had no marked effect on churning time (Figure 4). If more liquid fat is available, more crystals can be wetted and thus more connection between globules can occur. Thivilliers-Arvis et al. (2010) stated that the rate of partial coalescence reached a maximum value for a solid fraction of 10 to $15 \%$ in an emulsion of anhydrous milk fat. By increasing the level of SFC, the partial coalescence rate increases, as it is more likely that crystals protrude from the globule and bind the closest globule (Boode et al., 1993). However, at high levels of SFC, no liquid oil will be available, leading to a decrease in partial coalescence rate (Boode et al., 1993). In contrast, if not enough solid fat is formed, the fat globules behave as if liquid and crystals will not protrude and cause partial coalescence (Boode et 
al., 1993). However, the minimum SFC needed depends also on the globule size and on the size of the crystals formed (Boode et al., 1993). Small globules are less sensitive to partial coalescence because they decrease the possibility for encounters between globules; thereafter, a higher level of SFC is needed (Boode et al., 1993). By applying the theory of fractal aggregation of crystals, the diameter of a fractal aggregate should be smaller than the globule diameter to facilitate the formation of a fat crystal network through the globule (Boode et al., 1993; Fredrick et al., 2010). However, the higher the level of SFC, the greater the number of crystals that may protrude from the globules. It is well known that the FA composition of the milk varies considerably between breed of cow, feeding regimens, seasons, stages of lactation, and genetic variations (Jensen, 2002). The FA composition influences the crystallization of milk fat and thus the level of SFC. In general, higher amounts of polyunsaturated and long-carbon-chain FA are synthesized when the diet of the cow is based on a high amount of long-chain PUFA (e.g., in summer during pasture feeding). In contrast, in the winter, higher amounts of short-chain SFA are synthesized. The FA composition of the cream used in the present study (Table 1) was within the range reported from Danish cows kept in indoor housing systems (Poulsen et al., 2012). The content of short-chain FA (C4 to C16) is higher in winter cream, whereas long-chain FA (i.e., C18) and unsaturated and polyunsaturated FA (i.e., cis C18:1n-9, cis C18:2n-6, C18:3n-3, and 9,11 CLA) are lower in winter cream and higher in summer cream (Table 1). By increasing the carbon-chain length and the degree of unsaturation of the FA, the onset crystallization temperature decreases. Therefore, at the same ripening temperature used for winter cream, lower levels of SFC are expected for summer cream, which in turn leads to longer ripening and churning times.

Table 1. Average content and SE of the main FA composition of the winter cream used in this study

\begin{tabular}{lcl}
\hline FA & $\begin{array}{c}\text { Average } \\
(\%)\end{array}$ & $\begin{array}{c}\text { SE } \\
(\%)\end{array}$ \\
\hline C4 & 6.36 & 0.13 \\
C6 & 2.62 & 0.05 \\
C8 & 1.44 & 0.03 \\
C10 & 3.12 & 0.06 \\
C12 & 3.57 & 0.05 \\
C14 & 11.08 & 0.12 \\
C16:1 & 28.05 & 0.05 \\
C18 & 1.75 & 0.01 \\
cis C18:1n-9 & 11.06 & 0.13 \\
cis C18:2n-6 & 21.63 & 0.22 \\
918:3n-3 & 1.87 & 0.04 \\
9,11 CLA1 & 0.51 & 0.00 \\
C1 & 0.58 & 0.01 \\
\hline
\end{tabular}

${ }^{1} \mathrm{CLA}=$ conjugated linoleic acid.

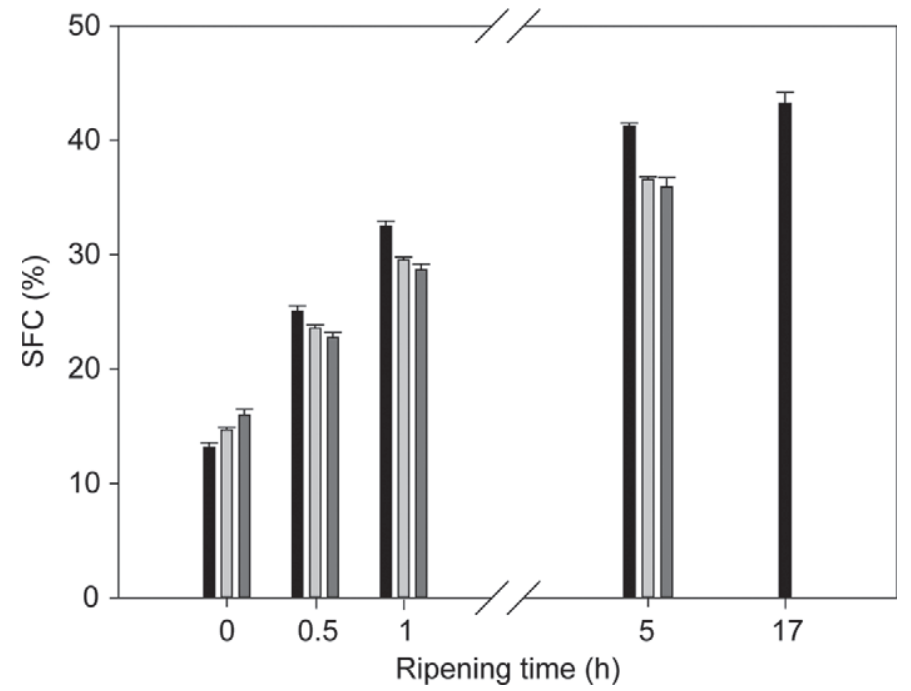

Figure 3. Level of solid fat content (SFC; \%) measured right after ripening of cream (black bar), after 7 min of churning (light gray bar), and just before butter grains aggregation (dark gray bar) for cream ripened for $0,0.5,1,5$, and $17 \mathrm{~h}$. Error bars show the SE.

Crystal polymorphism was investigated by wideand small-angle X-ray scattering during ripening and churning of the cream in a tabletop blender. During ripening at $10^{\circ} \mathrm{C}$, the first scattering was observed after 10 min, where 3 peaks corresponding to $3 \mathrm{~L}$ packing with long spacing of $74 \AA$ appeared (Figure 5a). Within the following $20 \mathrm{~min}$, this structure rearranged into $2 \mathrm{~L}$ packing with long spacing of $40.5 \AA$. The occurrence of 3L stacking in milk fat TAG is due to the high amount of short-chain FA. In general, 3L stacking is favored

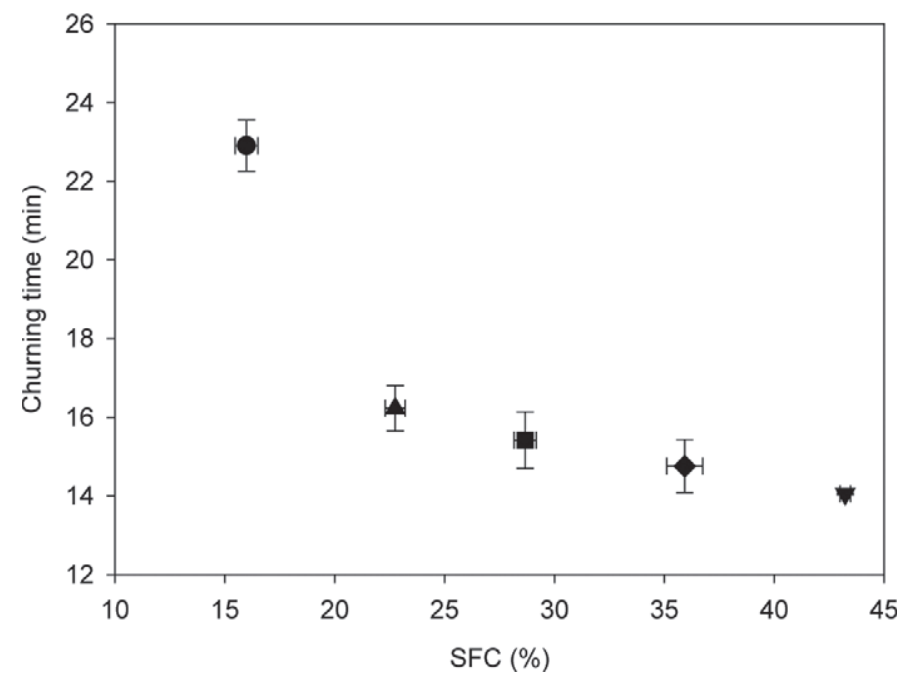

Figure 4. Relationship between level of solid fat content (SFC; \%) measured just before butter grains aggregation occurred versus churning time (min) for cream ripened for $0(\bullet), 0.5(\boldsymbol{\Delta}), 1(\boldsymbol{\square}), 5(\bullet)$ and $17 \mathrm{~h}(\boldsymbol{\nabla})$. Error bars show the SE. 


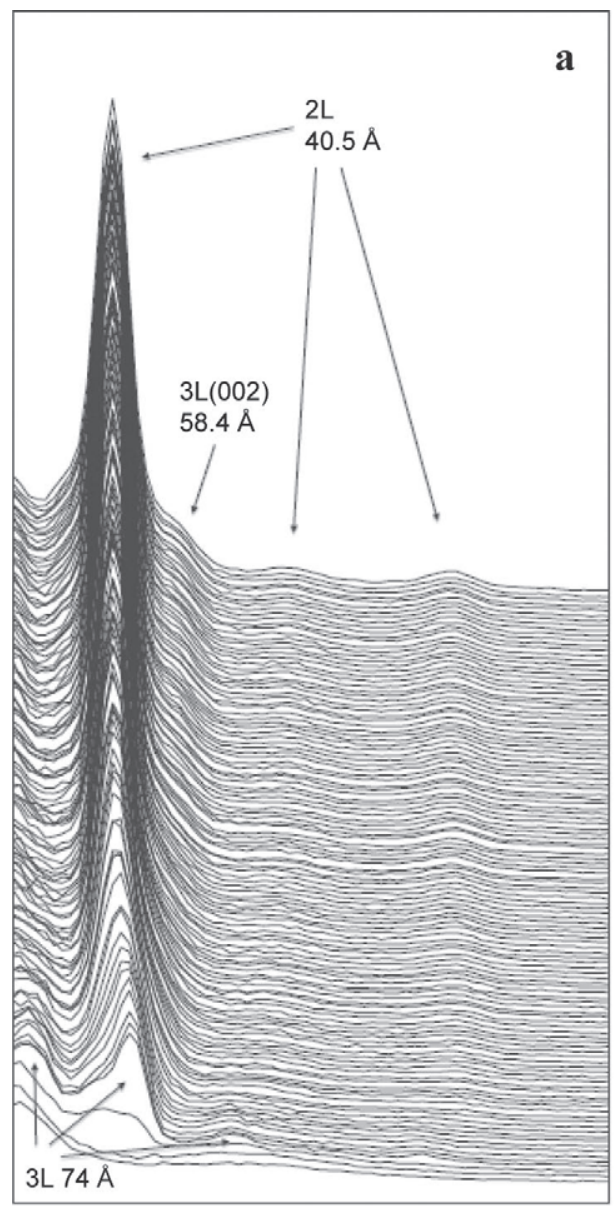

$\begin{array}{lllllllllll}0.1 & 0.15 & 0.2 & 0.25 & 0.3 & 0.35 & 0.4 & 0.45 & 0.5 & 0.55 & 0.6\end{array}$ $\mathrm{q}[1 / \mathrm{A}]$

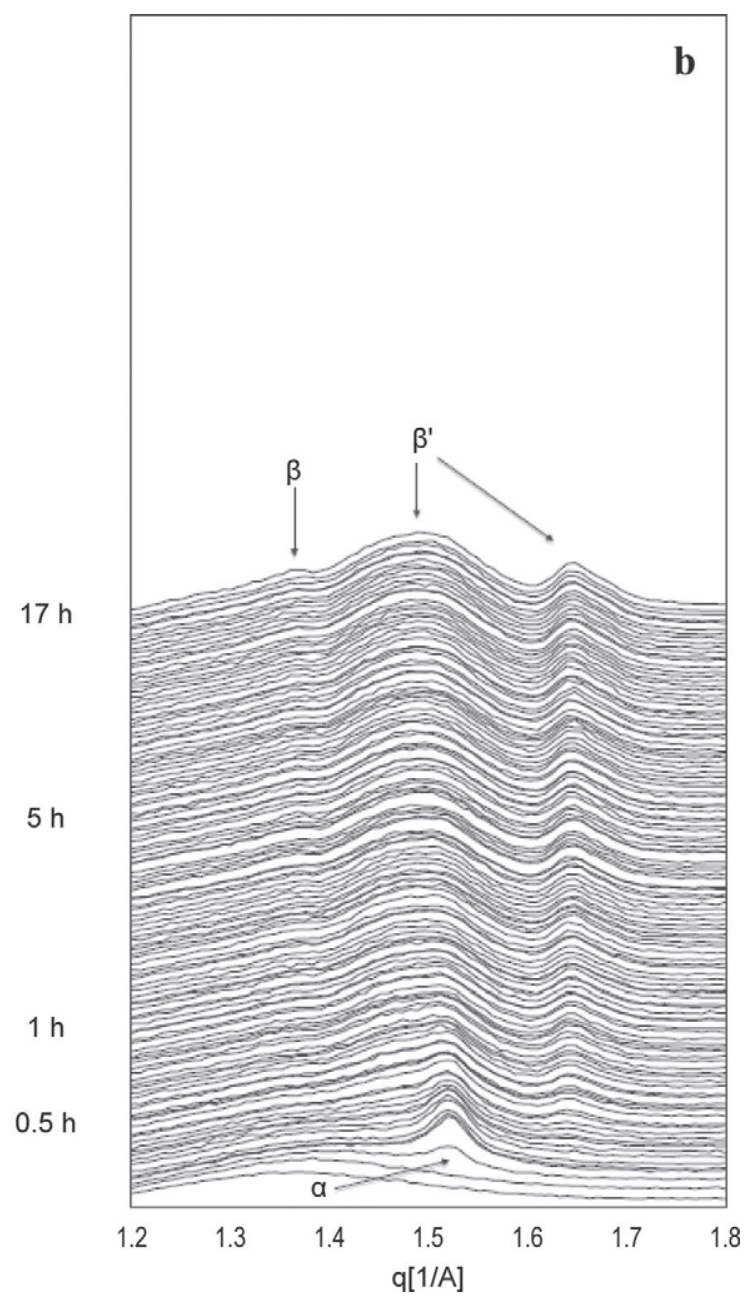

Figure 5. Small-angle X-ray scattering (a) and wide-angle X-ray scattering (b) spectra for cream ripened for $17 \mathrm{~h}$ at $10^{\circ} \mathrm{C}$. $2 \mathrm{~L}=$ double chain length structure; $3 \mathrm{~L}=$ triple chain length structure; $\beta=$ the polymorphic form of triacylglycerols (TAG) corresponding to the triclinic packing of the sub-cells; $\beta^{\prime}=$ the polymorphic form of TAG corresponding to the orthorhombic packing of the sub-cells; $q=$ scattering vector $[q=4 \pi / \lambda$ $\sin (\theta)$, where $\lambda=1.54 \AA$ is the X-ray wavelength and $\theta$ is half of the scattering angle].

when the difference in chain length between $\mathrm{FA}$ is equal to or higher than 4 carbon atoms (Small, 1986). The wide-angle scattering time evolution showed that the initial packing was hexagonal lateral chain packing $(4.15 \AA)$, corresponding to the unstable $\alpha$ form of TAG (Figure 5b; Small, 1986). After 33 min of ripening, the $\alpha$ form peak decreased in intensity and 2 new peaks corresponding to the orthorhombic sub-cell of the $\beta^{\prime}$ form of TAG (3.8 and $4.2 \AA$, respectively) emerged. Finally, after approximately $1 \mathrm{~h}$, peaks originating from the $\beta$ form of TAG started building up, showing a 58.4 $\AA 3 \mathrm{~L}$ packing and a weak peak at $4.6 \AA$. For the rest of ripening, these 3 crystal forms coexisted. These results agree with the study of Lopez et al. (2000), where $\alpha$ and $\beta^{\prime}$ forms were shown to coexist in the range of temperatures from 5 to $17^{\circ} \mathrm{C}$, when the cream was heated at $2^{\circ} \mathrm{C} / \mathrm{min}$ from -8 to $50^{\circ} \mathrm{C}$. Moreover, Lopez et al.
(2002), after storage of the cream at $4^{\circ} \mathrm{C}$ for more than $100 \mathrm{~h}$, found the coexistence of $\beta$ and $\beta^{\prime}$ with the same signatures of long spacing as found here (3L $58.4 \AA+$ 2L $40.5 \AA$ ). In Figure 6 , small- and wide-angle scattering results are shown from a sample ripened for $1 \mathrm{~h}$ and then at 3 subsequent times during churning. Before churning, weak traces of a $67 \AA 3 \mathrm{~L}$ packing were seen; however, this disappeared during churning, where only a $41.3 \AA 2 \mathrm{~L}$ structure was present (Figure 6a). From the wide-angle time evolution (Figure $6 \mathrm{~b}$ ), right after the ripening step, hexagonal lateral chain packing $(\alpha-4.15$ $\AA$ ) coexisted with $\beta^{\prime}{ }_{1}$ and $\beta^{\prime}{ }_{2}$ forms of TAG (3.8 and 4.2 $\AA$, respectively). During churning, the intensity of the $\alpha$ form decreased until it disappeared right after butter grains aggregation (Figure 6b), whereas the intensity of the $\beta^{\prime}{ }_{1}$ and $\beta^{\prime}{ }_{2}$ forms increased during the churning process. Small traces of the stable $\beta$ form seemed to 

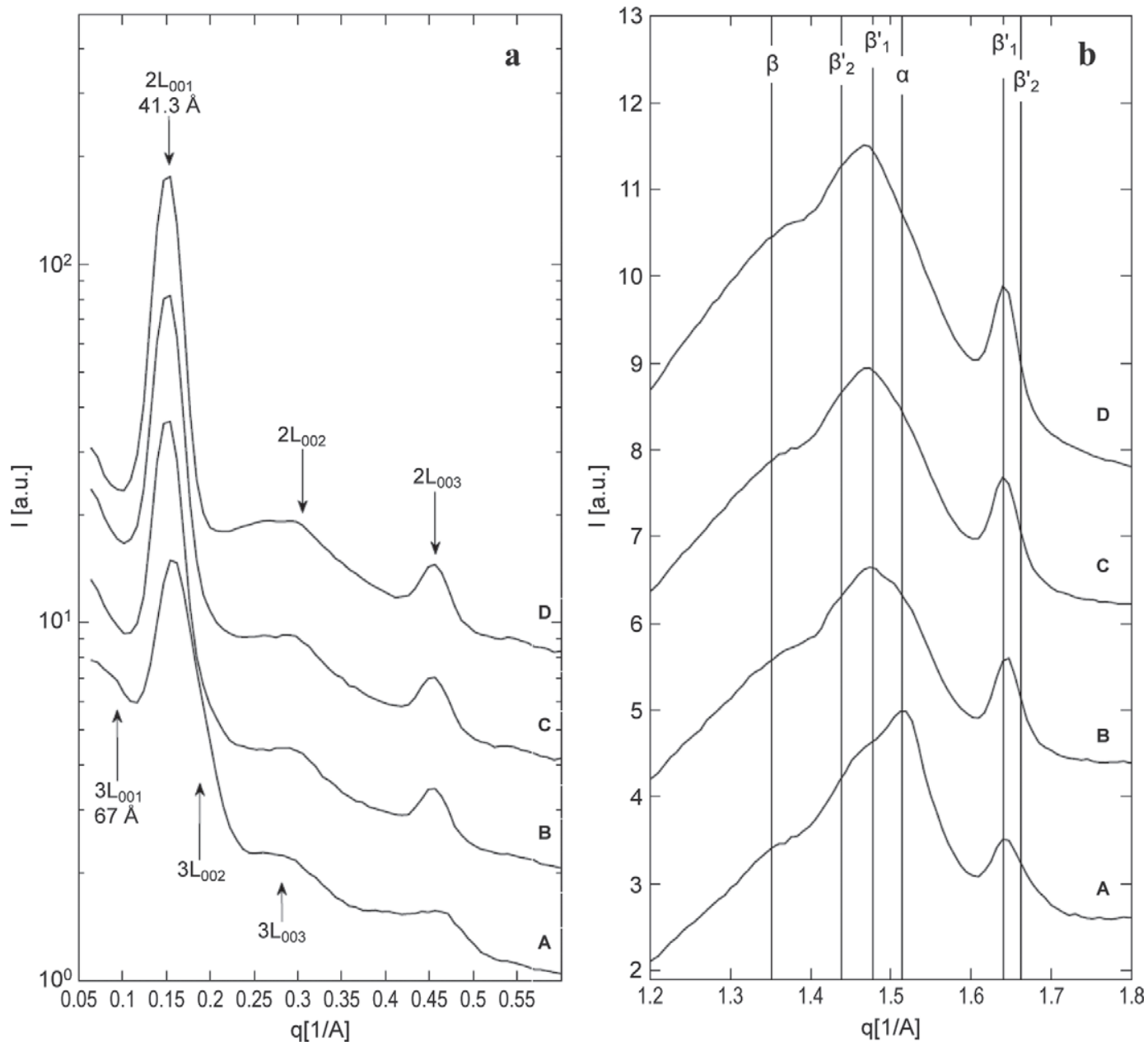

Figure 6. Small-angle X-ray scattering (a) and wide-angle X-ray scattering (b) spectra on cream ripened for $1 \mathrm{~h}$ at $10^{\circ} \mathrm{C}($ line $\mathrm{A})$ and then churned for $1.3 \mathrm{~min}$ (line B), $2.5 \mathrm{~min}$ (line C), and on butter grains (line D). Vertical lines indicate the position of the characteristic peaks of the crystal polymorphism. $2 \mathrm{~L}=$ double chain length structure; $3 \mathrm{~L}=$ triple chain length structure; $\beta=$ the polymorphic form of triacylglycerols (TAG) corresponding to the triclinic packing of the sub-cells; $\beta^{\prime}=$ the polymorphic form of TAG corresponding to the orthorhombic packing of the sub-cells; $\mathrm{q}=$ scattering vector $[\mathrm{q}=4 \pi / \lambda \sin (\theta)$, where $\lambda=1.54 \AA$ is the X-ray wavelength and $\theta$ is half of the scattering angle].

be present already in the nonchurned sample and appeared to be constant throughout churning. Churning of the cream favored the transition from the $\alpha$ form to the $\beta^{\prime}$ form. It has been previously reported that shear forces accelerate the phase transition in milk fat (Mazzanti et al., 2003). In the present study, we speculated that differences in shear rate (e.g., between the shear rate used in the starch cell and in the tabletop blender, or between the model system and a typical continuous butter-making machine) do not affect the final crystal polymorphisms. The onset time for crystal transition to a more stable form might slightly change; however, this will not affect the formation of butter grains. Here, no relationship was observed between polymorphism and vulnerability to partial coalescence (i.e., the $\beta^{\prime}$ form did not trigger partial coalescence). Furthermore, the crystal polymorphism was not influenced by the ripening time if this was higher than $1 \mathrm{~h}$.

The thermal behavior of cream right after ripening showed 2 melting peaks: the medium-melting fraction (MMF) and the high-melting fraction (HMF; Figure 7). After 5 min of churning, only the HMF was present (Figure 7). The melting of the MMF was caused by the increase in temperature from the ripening to the churning step, which also was supported by the decrease in SFC (Figure 3). By increasing the ripening time from $0 \mathrm{~h}$ to 0.5 and $1 \mathrm{~h}$, the melting point of the MMF significantly $(P<0.0001)$ increased. No significant differences in melting point of the MMF were observed between the cream ripened for $1 \mathrm{~h}$ compared with $5 \mathrm{~h}$. Both ripening and churning time contributed, although to a different extent, to the melting point of the HMF. 


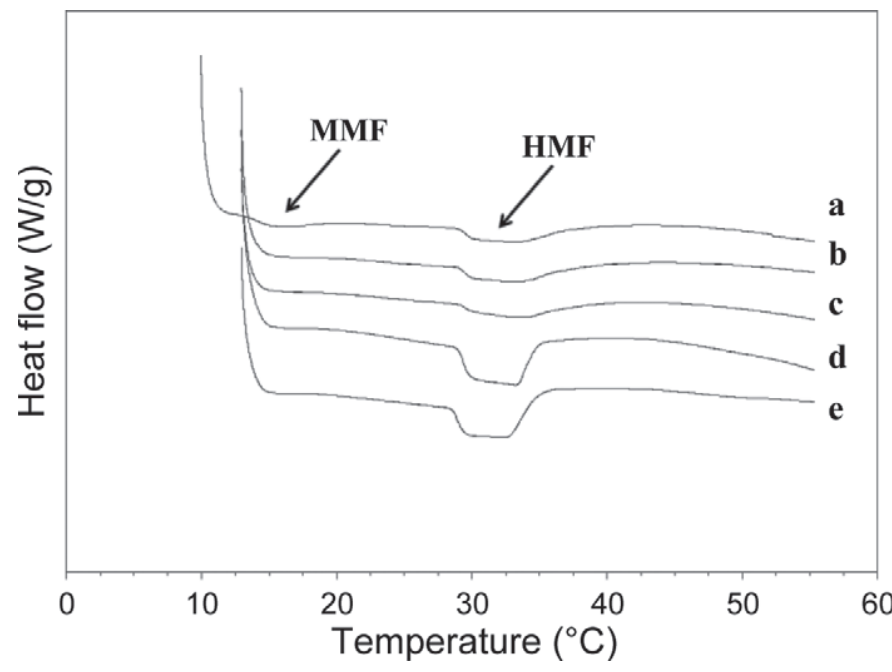

Figure 7. Thermograph of cream ripened for $5 \mathrm{~h}$ (a), and churned for $5 \mathrm{~min}$ (b) or $10 \mathrm{~min}(\mathrm{c})$, just before butter grains aggregation occurred (d), and on butter grains (e). The heating rate was $5^{\circ} \mathrm{C} / \mathrm{min}$. $\mathrm{MMF}=$ medium-melting fraction; $\mathrm{HMF}=$ high-melting fraction.

The contribution from the churning time was stronger $(P<0.0001)$ than the one $(P<0.05)$ from the ripening time. Moreover, interaction between the variables was observed. By increasing the churning time, the melting point of the HMF decreased and reached a significantly $(P<0.01)$ lower value after phase inversion of the emulsion on the butter grains compared with the cream after ripening (Figure 7). Longer ripening time led to the crystallization of the more stable crystals and thus to an increase in melting point of the MMF. At a ripening time longer than $1 \mathrm{~h}$, no further increase in melting point of the MMF was observed, as confirmed by the wide-angle scattering, where no changes in polymorphic forms were observed after $1 \mathrm{~h}$ of ripening (Figure 5b). However, the higher temperature and the shear forces applied during churning led to the melting of the less stable crystals and thus to a decrease in melting point of the HMF.

\section{CONCLUSIONS}

Summarizing the study, longer ripening time led to a higher rate of fat crystallization and thus to a higher degree of partial coalescence and to larger particles in the emulsion. No further decrease in churning time was observed after $0.5 \mathrm{~h}$ of ripening. However, the crystal polymorphism and the melting behavior did not change when the ripening time was higher than $1 \mathrm{~h}$. This indicates that the crystallization state that promoted partial coalescence and consequently phase inversion of the emulsion (and thus, butter grains aggregation) occurred during the first hour of cream ripening at $10^{\circ} \mathrm{C}$. However, these conclusions are based on a model system study in which conditions (e.g., dimensions of the ripening tanks, design of the ripening tanks and impeller, and the shear rate) differ from the typical butter-manufacturing plant. The mass transfer of the latent heat is affected by the dimension of the ripening tank (e.g., larger volume gives a slower mass transfer of the latent heat). In addition, the flow of the fat globules during churning is affected by the shear rate used and by the design of the impeller (e.g., higher shear rate leads to a faster butter grains aggregation). Consequently, the crystallization time and hence the partial coalescence rate of milk fat globules is expected to be different from a model system to a typical buttermanufacturing plant. However, the present study gives a general overview of the fundamental processes of crystallization and polymorphism of milk fat occurring during ripening and churning of cream. Therefore, the dairy industry will benefit from these insights on the optimization of butter manufacturing.

\section{ACKNOWLEDGMENTS}

The authors thank Arla Foods (Viby J, Denmark); the Ministry of Food, Agriculture and Fisheries (Copenhagen, Denmark; grant no. 3414-09-02406); the Danish Dairy Research Foundation (Aarhus, Denmark); and FOOD Denmark (Frederiksberg, Denmark) for financing the $\mathrm{PhD}$ project.

\section{REFERENCES}

Barfod, N., and N. Krog. 1987. Destabilization and fat crystallization of whippable emulsions (toppings) studied by pulsed NMR. J. Am. Oil Chem. Soc. 64:112-119.

Boode, K. 1992. Partial coalescence in oil-in-water emulsions. $\mathrm{PhD}$ Thesis. Wageningen University, Wageningen, the Netherlands.

Boode, K., and P. Walstra. 1993. Partial coalescence in oil-in-water emulsions 1. Nature of the aggregation. Colloids Surf. A Physicochem. Eng. Asp. 81:121-137.

Boode, K., P. Walstra, and A. E. A. de Groot-Mostert. 1993. Partial coalescence in oil-in-water emulsions 2. Influence of the properties of the fat. Colloids Surf. A Physicochem. Eng. Asp. 81:139-151.

Bugeat, S., V. Briard-Bion, J. Pérez, P. Pradel, B. Martin, P. Lesieur, C. Bourgaux, M. Ollivon, and C. Lopez. 2011. Enrichment in unsaturated fatty acids and emulsion droplet size affect the crystallization behaviour of milk triacylglycerols upon storage at 4C. Food Res. Int. 44:1314-1330.

Darling, D. F. 1982. Recent advances in the destabilization of dairy emulsions. J. Dairy Res. 49:695-712.

Drelon, N., E. Gravier, L. Daheron, L. Boisserie, A. Omari, and F. Leal-Calderon. 2006. Influence of tempering on the mechanical properties of whipped dairy creams. Int. Dairy J. 16:1454-1463.

Fredrick, E., P. Walstra, and K. Dewettinck. 2010. Factors governing partial coalescence in oil-in-water emulsions. Adv. Colloid Interface Sci. $153: 30-42$.

Funahashi, H., and J. Horiuchi. 2008. Characteristics of the churning process in continuous butter manufacture and modelling using an artificial neural network. Int. Dairy J. 18:323-328.

Goff, H. D. 1997. Instability and partial coalescence in whippable dairy emulsions. J. Dairy Sci. 80:2620-2630. 
Jensen, R. G. 2002. The composition of bovine milk lipids: January 1995 to December 2000. J. Dairy Sci. 85:295-350.

Johansson, D. 1994. Colloids in fats: The fat crystal as a functional particle. PhD Thesis. Lund University, Lund, Sweden.

Larsson, K., and K. Larsson. 1994. Lipids: Molecular organization, physical functions and technical applications. The Oily Press, Dundee, UK.

Lopez, C., C. Bourgaux, P. Lesieur, and M. Ollivon. 2002. Crystalline structures formed in cream and anhydrous milk fat at $4{ }^{\circ} \mathrm{C}$. Lait 82:317-335.

Lopez, C., P. Lesieur, G. Keller, and M. Ollivon. 2000. Thermal and structural behavior of milk fat: 1. Unstable species of cream. J. Colloid Interface Sci. 229:62-71.

Mazzanti, G., S. E. Guthrie, E. B. Sirota, A. G. Marangoni, and S. H. J. Idziak. 2003. Orientation and phase transitions of fat crystals under shear. Cryst. Growth Des. 3:721-725.

Poulsen, N. A., F. Gustavsson, M. Glantz, M. Paulsson, L. B. Larsen, and M. K. Larsen. 2012. The influence of feed and herd on fatty acid composition in 3 dairy breeds (Danish Holstein, Danish Jersey, and Swedish Red). J. Dairy Sci. 95:6362-6371.

Rousseau, D. 2000. Fat crystals and emulsion stability-A review. Food Res. Int. 33:3-14.

Samuelsson, E., and K. I. Petersson. 1937. Årsskrift för Alnarps lantbruksmejeriog trädgårdsinstitut. Pages 159-194 in Developments in Dairy Chemistry. Volume 2. P. F. Fox, ed. Applied Science Publishers, London, UK.

Sato, K. 2001. Crystallization behaviour of fats and lipids-A review. Chem. Eng. Sci. 56:2255-2265.

Small, D. M. 1986. The Physical Chemistry of Lipids: From Alkanes to Phospholipids. D. J. Hanahan, ed. Plenum Press, New York, NY.

Thivilliers-Arvis, F., E. Laurichesse, V. Schmitt, and F. Leal-Calderon. 2010. Shear-induced instabilities in oil-in-water emulsions comprising partially crystallized droplets. Langmuir 26:16782-16790.

van Boekel, M. A. J. S., and P. Walstra. 1981a. Stability of oil-inwater emulsions with crystals in the disperse phase. Colloids Surf. 3:109-118.

van Boekel, M. A. J. S., and P. Walstra. 1981b. Effect of Couette flow on stability of oil-in-water emulsions. Colloids Surf. 3:99-107.

Vanapalli, S. A., J. Palanuwech, and J. N. Coupland. 2002. Influence of fat crystallization on the stability of flocculated emulsions. J. Agric. Food Chem. 50:5224-5228.

Wiking, L., E. Fredrick, and K. Dewettinck. 2009. Phospholipids delay crystallisation of milk fat. Milchwissenschaft 4:376-379.

Xu, W., A. Nikolov, and D. T. Wasan. 2005. Shear-induced fat particle structure variation and the stability of food emulsions: I. Effects of shear history, shear rate and temperature. J. Food Eng. 66:97-105. 